University of Windsor

Scholarship at UWindsor

\title{
Detection and discrimination of simple and complex sounds by hearing-impaired Belgian Waterslager canaries
}

\author{
A. M. Lauer \\ University of Windsor \\ R. J. Dooling \\ University of Windsor \\ Leek, M.R. Leek, M.R. \\ University of Windsor \\ K. Poling \\ University of Windsor
}

Follow this and additional works at: https://scholar.uwindsor.ca/biologypub

Part of the Biology Commons

\section{Recommended Citation}

Lauer, A. M.; Dooling, R. J.; Leek, M.R., Leek, M.R.; and Poling, K., "Detection and discrimination of simple and complex sounds by hearing-impaired Belgian Waterslager canaries" (2007). Journal of the Acoustical Society of America, 122, 6, 3615-3627.

https://scholar.uwindsor.ca/biologypub/1057

This Article is brought to you for free and open access by the Department of Biological Sciences at Scholarship at UWindsor. It has been accepted for inclusion in Biological Sciences Publications by an authorized administrator of Scholarship at UWindsor. For more information, please contact scholarship@uwindsor.ca. 
Detection and discrimination of simple and complex sounds by hearing-impaired Belgian Waterslager canaries

Amanda M. Lauer, , Robert J. Dooling, and , , Marjorie R. Leek and , , Kirsten Poling and , and

Citation: The Journal of the Acoustical Society of America 122, 3615 (2007); doi: 10.1121/1.2799482

View online: http://dx.doi.org/10.1121/1.2799482

View Table of Contents: http://asa.scitation.org/toc/jas/122/6

Published by the Acoustical Society of America 


\title{
Detection and discrimination of simple and complex sounds by hearing-impaired Belgian Waterslager canaries
}

\author{
Amanda M. Lauer ${ }^{\text {a) }}$ and Robert J. Dooling \\ Department of Psychology, University of Maryland, College Park, Maryland 20742 \\ Marjorie R. Leek \\ National Center for Rehabilitative Auditory Research, Portland VA Medical Center, 3710 SW \\ US Veterans Hospital Road, Portland, Oregon 97207 \\ Kirsten Poling ${ }^{\text {b) }}$ \\ Department of Psychology, University of Maryland, College Park, Maryland 20742
}

(Received 31 January 2007; revised 17 September 2007; accepted 18 September 2007)

\begin{abstract}
Belgian Waterslager canaries (BWC) are bred to produce a distinctive low-pitched song with energy restricted to a lower range of frequencies than in other types of canaries. Previous studies have shown a high frequency hearing loss primarily above $2000 \mathrm{~Hz}$ that is related to hair cell abnormalities in BWC, but little is known about auditory perception in these birds. Here, frequency, duration, and intensity discrimination, temporal integration, gap detection, and discrimination of temporally reversed harmonic complexes in BWC were measured and compared to normal-hearing non-BWC. BWC had excellent frequency discrimination ability at $1000 \mathrm{~Hz}$, but showed poor frequency discrimination compared to non-BWC at frequencies in the region of hearing loss. Duration and intensity discrimination were not adversely affected in BWC. Temporal integration was reduced in BWC, except at $2000 \mathrm{~Hz}$. Gap detection and discrimination of temporally reversed stimuli were somewhat better in BWC than in non-BWC. Those tests that relied primarily on temporal processing were less affected by the cochlear damage in BWC than tests that probably relied more on audibility and spectral analysis. Thus, despite significant high frequency hearing loss and extensive damage along the basilar papilla, BWC retain relatively good hearing abilities under many conditions. () 2007 Acoustical Society of America. [DOI: 10.1121/1.2799482]
\end{abstract}

PACS number(s): 43.66.Gf, 43.66.Sr, 43.80.Lb, 43.66.Fe [JAS] Pages: 3615-3627

\section{INTRODUCTION}

The canary (Serinus canaria) is a species of cardueline finch that produces intricate songs during a yearly breeding season. Domesticated canary song is noted for its long sequences of "tours" consisting of consecutive repetitions of relatively tonal notes or syllables (e.g., Güttinger, 1985). Several strains of canaries are bred for particular song characteristics, while other strains are bred for body shape or plumage. The Belgian Waterslager canary (BWC) is one of the types bred for song. BWC song contains distinct syllables referred to by breeders as "water notes." The frequency range of BWC song lies mainly between 1000 to $4000 \mathrm{~Hz}$ (Nottebohm and Nottebohm, 1978; Güttinger, 1985; Wright et al., 2004). The song repertoire consists of approximately 20-35 different syllable types (Marler and Waser, 1977; Nottebohm and Nottebohm, 1978; Güttinger, 1985). In contrast, songs produced by nonBWC strains typically have broader frequency ranges $(1000-6500 \mathrm{~Hz})$ and more syllable types (Güttinger, 1985; Lohr et al., 2004).

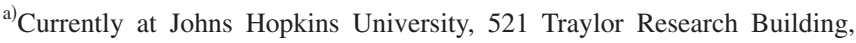
720 Rutland Avenue, Baltimore, MD 21205. Electronic mail: alauer2@jhmi.edu

${ }^{b)}$ Currently at Department of Biological Sciences, University of Windsor, 401 Sunset Avenue, Windsor, Ontario, Canada N9B 3P4.
}

BWC have been the subject of many behavioral and neurobiological studies of song learning and production. Male BWC normally learn their songs from their fathers and male siblings, though they can learn from other sources of acoustic input (Marler and Waser, 1977; Waser and Marler, 1977). Recent work has shown that song learning by juvenile BWC is largely influenced by tutor song, and that young birds are capable of imitating synthesized song with a structure that does not resemble normal adult song, highlighting the substantial influence of acoustic input during song learning (Gardner et al., 2005).

BWC have been found to have a hereditary hearing loss, primarily above $2000 \mathrm{~Hz}$, linked to hair cell abnormalities (Gleich et al., 1994, 1995; Okanoya and Dooling, 1985, 1987; Okanoya et al., 1990; Wright et al., 2004), which is presumably due to breeding for special song characteristics. Many hair cells are missing or damaged, and many of the remaining hair cells have abnormal stereocilia bundles (Gleich et al., 1994, 1995; Weisleder and Park, 1994; Weisleder et al., 1996). Despite a reduction in the number of hair cells and auditory nerve fibers in BWC (Gleich et al., 2001), cell number is not significantly reduced, compared to non-BWC, in auditory brainstem structures responsible for encoding temporal information (nucleus magnocellularis and nucleus laminaris; Kubke et al., 2002). However, the overall volumes of nucleus magnocellularis and nucleus laminaris are reduced in BWC, an effect that has been attributed to smaller 
cell size. Intriguingly, the hearing deficit and hair cell abnormalities develop after hatch, but before the bird reaches adulthood (Brittan-Powell et al., 2002; Ryals and Dooling, 2002). Thus, the peripheral auditory system of the BWC is compromised during the period of initial song learning, as well as during yearly periods of song modification in adults.

Auditory information is crucial for the development and maintenance of species-specific vocalizations in canaries. Canaries raised in isolation or masking noise develop relatively simple songs compared to birds raised in the presence of tutors (Marler and Waser, 1977). Surgical deafening during adulthood can result in the degradation of song in canaries (Nottebohm and Nottebohm, 1976). The ability of a bird to resolve acoustic changes in tutor song must directly influence the content of its vocalizations. The animal needs to distinguish one call or note from another in order to develop and maintain a normal vocal repertoire, and it must be able to focus its attention on important acoustic information to effectively communicate with other members of its strain or species. More specifically, the bird must be able to resolve changes in frequency, time, and intensity. It must also be able to combine complex interactions of the acoustic dimensions to perceive and respond to naturally occurring sounds.

The behavioral consequences of the pathology in BWC, other than elevated high frequency thresholds, are not well understood because few studies have investigated auditory perception in BWC. Separate studies have shown that frequency selectivity and phase effects on masking are reduced in BWC (Lauer and Dooling, 2002; Lauer et al., 2002; 2006). These studies suggest that there are deficits in the active processing mechanisms of the basilar papilla that result in abnormal encoding in the auditory periphery of BWC. The effects of the hair cell pathology on other aspects of auditory perception are unknown.

The unique vocalizations coupled with abnormal inner ear pathology in BWC may be related to strain-specific perceptual predispositions. These perceptual predispositions are likely to influence song learning and preference and withinstrain communication. The following series of experiments was chosen to encompass some of the types of acoustic cues that are present in canary vocalizations. We investigated discrimination of changes in the frequency, duration, and intensity of pure tones, temporal integration of pure tones, gap detection, and discrimination of temporally reversed harmonic complexes in BWC and non-BWC. These studies are part of a larger effort to assess auditory perception in BWC. These birds are the only known animal in which we can investigate the relationships among heredity, auditory system structural abnormalities, vocal learning and vocal production, hair cell regeneration, and hearing abilities. Together, these experiments provide perhaps the most comprehensive investigation of hearing abilities in an animal with earlyonset hereditary hearing loss.

\section{GENERAL METHODS}

\section{A. Subjects}

Adult BWC and adult non-BWC were used in each experiment. The same birds did not participate in all experi- ments due to deaths. A total of $8 \mathrm{BWC}$ and 7 non-BWC were used. Birds were housed in an avian vivarium at the University of Maryland and kept on a 12/12 h photoperiod. All birds were maintained at approximately $85-90 \%$ of their free-feeding weight, and had free access to water and grit. The Animal Care and Use Committee of the University of Maryland (College Park, MD) approved the care and use of animals in this study (A3270).

\section{B. Apparatus}

Birds were tested in a wire cage $(26 \times 18 \times 14 \mathrm{~cm})$ mounted in a sound-attenuated chamber (Industrial Acoustics Company, Bronx, NY, IAC-3) lined with acoustic foam. The test cage consisted of a perch, an automatic feeder (food hopper), and two response keys made of red and green $8 \mathrm{~mm}$ light-emitting diodes (LEDs) attached to two microswitches. The left key (red LED) was designated as the observation key, and the right key (green LED) was designated as the report key. A speaker (KEF Model 80C, England) was mounted from the roof of the sound-attenuated chamber at a $45^{\circ}$ angle aimed toward the front of the bird, approximately $35 \mathrm{~cm}$ from the bird's head. Birds were monitored at all times by an overhead video camera system during testing.

The experiments were controlled by an IBM Pentium III microcomputer operating Tucker-Davis Technologies (TDT, Gainesville, FL) System 2 modules. Stimuli were generated with a 40,000 $\mathrm{Hz}$ sampling rate prior to the beginning of the experiment, stored digitally, and output via a timing generator (TDT, Model TG6) to a four-channel D/A converter (TDT, Model DA3-4). Each signal was then output from a separate channel of the D/A converter to a digital attenuator (TDT, Model PA4) and amplifier (TDT, Model HB6) to the speaker. Stimulus calibration was performed periodically using a Larson-Davis sound level meter (Model 825, Provo, UT) attached to a $\frac{1}{2}$ in. microphone positioned in the place normally occupied by the birds' head during testing.

\section{Training and testing procedures}

Birds were trained to peck the observation key for a random interval of 2-6 s during a repeating background sound or in quiet. The background sound was alternated with a target sound twice after this random interval. The bird was required to peck the report key within $2 \mathrm{~s}$ of this target/ background alternation to receive a food reward. A report key peck during this time was recorded as a hit. If the bird failed to peck the report key within $2 \mathrm{~s}$ of the target/ background alternation, it was recorded as a miss. Incorrect report key pecks were punished with a time-out period during which the chamber lights and LEDs were extinguished. Time-out periods lasted from 1 to $10 \mathrm{~s}$ depending on an individual bird's performance. On $30 \%$ of all trials, sham trials were presented during which there was no target/background alternation. Pecks to the report key during sham trials were recorded as false alarms and punished with time-out periods. This procedure has been described in more detail elsewhere (Dooling and Okanoya 1995).

Experimental sessions consisted of approximately 50100 trials, and birds were tested twice a day, 5 days a week. 
Within a block of 10 trials, the bird was presented with 7 target sounds and 3 sham trials in a random order. All test sessions were automated using a custom-designed Visual Basic computer program. Data were stored digitally and analyzed using commercially available statistics software and a custom-designed analysis program.

The general procedures for measuring detection and discrimination thresholds in Experiments 1-5 were similar. The order of conditions tested was randomly chosen for each individual bird. Birds were required to peck the observation key during silence (detection) or a repeating background (discrimination). After a random interval, the background was alternated with a target sound. Target sounds were presented using the Method of Constant Stimuli. Thresholds were defined as the frequency of the target detected $50 \%$ of the time $(\mathrm{Pc})$, corrected for the false alarm $(\mathrm{FA})$ rate $\left[\mathrm{Pc}^{*}=(\mathrm{Pc}-\mathrm{FA}) /(1-\mathrm{FA})\right]$ (Gescheider, 1985; Dooling and Okanoya, 1995). In Experiment 6, all target sounds were identical during a testing session. No thresholds were measured in Experiment 6. Instead, percent correct discriminations were measured.

Each bird ran a minimum of 300 trials on each experimental condition, and the last 200 trials once behavior stabilized were used for analysis. Behavior was considered stable if the threshold did not change by more than $1 / 3$ of the increment step size within the last two 100-trial blocks.

Prior to testing in the experiments described in the following, absolute thresholds for a range of pure tone frequencies were measured for each bird to confirm normal hearing in non-BWC and hearing impairment in BWC. Average absolute thresholds and thresholds from individual birds are shown in Fig. 1. These thresholds are consistent with previously reported behavioral thresholds in BWC and non-BWC (Okanoya and Dooling, 1985, 1987; Okanoya et al., 1990).

\section{EXPERIMENT 1-FREQUENCY DISCRIMINATION}

Canary vocalizations consist of mainly tonal elements (e.g., Güttinger, 1985). Despite the importance of frequency as a salient feature of avian vocalizations, most tests reveal that birds are not especially sensitive to frequency changes compared to other vertebrates. In general, birds are able to detect less than a 1\% change in frequency between 1000 and $4000 \mathrm{~Hz}$, whereas humans can detect less than a $0.5 \%$ change (reviewed in Dooling et al., 2000). In this experiment, frequency difference limens (FDLs) at 1000, 2000, and $4000 \mathrm{~Hz}$ were measured in BWC and non-BWC at a range of sound levels. Budgerigars with mild residual hearing losses 4-6 weeks following kanamycin exposure do not show significant increases in FDLs for 1000 and $2860 \mathrm{~Hz}$ tones presented at $65 \mathrm{~dB}$ sound pressure level (SPL) (Dooling et al., 2006). Accordingly, BWC may only show increased FDLs at frequencies where the hearing loss is most severe (above $2000 \mathrm{~Hz})$.

\section{A. Methods: Stimuli and procedures}

Background stimuli were 1000, 2000, and $4000 \mathrm{~Hz}$ pure tones. Target stimuli were pure tones with frequencies ranging from 10 to $700 \mathrm{~Hz}$ above the background frequency, with a step size of $10,20,50$, or $100 \mathrm{~Hz}$ depending on the background frequency and the bird's estimated threshold. All stimuli were $400 \mathrm{~ms}$ in duration with rise/fall times of $20 \mathrm{~ms}$. Birds were tested at a range of sound levels at each frequency. Stimuli were presented at 50,60, 70, and $80 \mathrm{~dB}$ SPL for the $1000 \mathrm{~Hz}$ background condition; 40, 50, 60, 70, and $80 \mathrm{~dB}$ SPL for the $2000 \mathrm{~Hz}$ background condition; and $30,40,50,60,70$, and $80 \mathrm{~dB}$ SPL for the $4000 \mathrm{~Hz}$ background condition. It was not possible to test BWC at all of the levels that non-BWC were tested on due to their high absolute thresholds. To reduce potential loudness cues, the sounds were randomly roved by $\pm 6 \mathrm{~dB}$ on each stimulus presentation.

Thresholds for detecting increments in tone frequency were measured in 4 non-BWC and 4 BWC. The average false alarm rate was $2.8 \%$ for non-BWC and $3.6 \%$ for BWC. Data from sessions with false alarm rates larger than $18 \%$ or with a hit rate less than $80 \%$ for the two targets with the largest frequency change were excluded from analysis. Four percent of the data from non-BWC were discarded, and 5\% of the data from BWC were discarded.

\section{B. Results and discussion}

Mean FDLs expressed as percent of the background frequency are shown in Fig. 2 for BWC and non-BWC for (A) 1000, (B) 2000, and (C) $4000 \mathrm{~Hz}$. Data points for individual BWC are shown where no average data could be computed because it was not possible to measure a FDL at that point for all subjects due to stimulus inaudibility. As reported in other species of small birds (Dooling and Saunders, 1975; Kuhn and Saunders, 1980; Sinnott et al., 1980), non-BWC were able to detect a change in frequency as small as 1-2\% at high sound levels. Non-BWC showed a decrease of about three percentage points in FDLs with increasing level at $1000 \mathrm{~Hz}$, and less than one percentage point at 2000 and $4000 \mathrm{~Hz}$. The largest FDLs were at $1000 \mathrm{~Hz}$ for non-BWC. It should be noted that of the three frequencies tested, nonBWC showed the highest absolute thresholds at $1000 \mathrm{~Hz}$ (see Fig. 1).

BWC showed larger FDLs than non-BWC at 2000 and $4000 \mathrm{~Hz}$. The largest FDLs occurred at $4000 \mathrm{~Hz}$, where absolute thresholds were most elevated. At $1000 \mathrm{~Hz}$, BWC showed a trend toward slightly better FDLs at the two lowest levels tested. A one-tailed t-test revealed that BWC had significantly lower FDLs for $1000 \mathrm{~Hz}$ presented at $60 \mathrm{~dB}$ SPL $[t(6)=-2.687, p<0.05]$. BWC showed very little change in FDLs with increasing level at 1000 and $2000 \mathrm{~Hz}$. The two BWC that were tested at multiple levels at $4000 \mathrm{~Hz}$ showed a decrease in FDL with increasing sound level. Because BWC were not tested at all of the levels at which non-BWC were tested, it was not possible to perform an analysis of variance (ANOVA) on the entire set of data. Thus, a mixed factor ANOVA (strain $\times$ frequency) was conducted on the FDLs for the $80 \mathrm{~dB}$ SPL condition only. There was no significant effect of frequency; however, there was a significant effect of strain $[F(1,6)=30.484, p=0.001]$. The interaction 


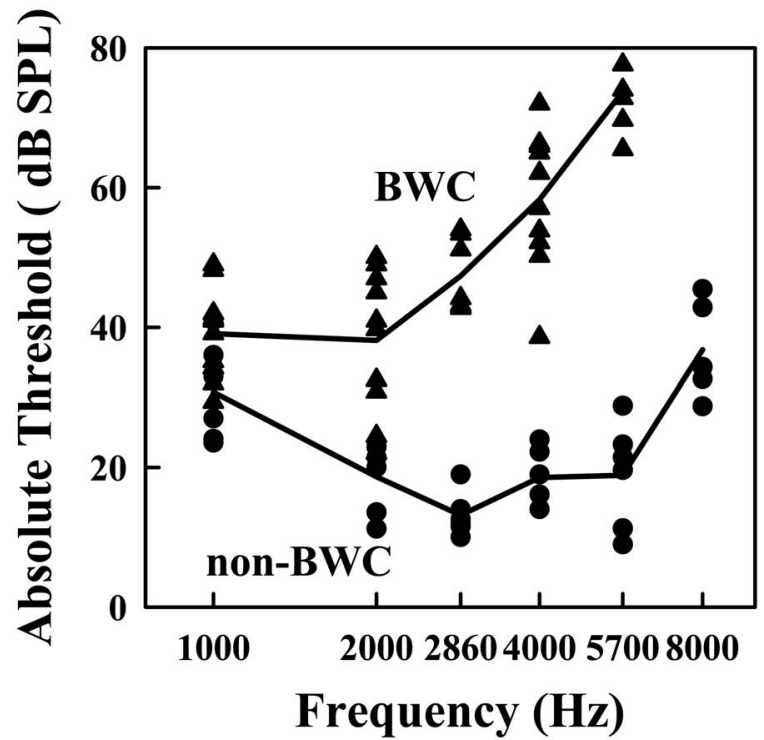

FIG. 1. Pure tone thresholds for average (solid lines) and individual nonBWC (circles) and BWC (triangles).

between factors was not significant. Strain differences in FDLs (BWC FDL-non-BWC FDL) at $80 \mathrm{~dB}$ SPL averaged across frequency are shown in Fig. 2(d).

The increased FDLs in the region of hearing loss in BWC compared to non-BWC are consistent with reports of reduced frequency discrimination abilities in animals with combined outer and inner hair cell damage. In cats and chinchillas, complete destruction of outer hair cells (OHCs) in the region of the basilar membrane corresponding to the test frequency does not result in increased FDLs; however, damage that results in the destruction of over $50 \%$ of inner hair cells (IHCs) and complete destruction of OHCs does result in increased FDLs (Nienhuys and Clark, 1978; Prosen et al., 1989). BWC show damage primarily to efferently innervated hair cells, but also show abnormal afferent hair cells. Thus, the decreased sensitivity to changes in frequency at 2000 and $4000 \mathrm{~Hz}$ is not surprising. However, the fact that frequency discrimination is better in BWC compared to non-BWC at $1000 \mathrm{~Hz}$ at $60 \mathrm{~dB}$ SPL despite the presence of significant hair cell abnormalities across the entire basilar papilla suggests that (1) there is not enough damage to hair cells with characteristic frequencies near $1000 \mathrm{~Hz}$ to impair frequency discrimination or (2) frequency discrimination at high and low frequencies is accomplished through different mechanisms. This hypothesis has been suggested by Sek and Moore (1995) to explain frequency discrimination results from human listeners. Temporal mechanisms of frequency discrimination may be dominant in lower frequencies, whereas, as phase locking is reduced at higher frequencies, spectral mechanisms have more importance. BWC may have particularly good temporal processing, but poorer than normal spectral processing due to their cochlear damage, providing at least a partial explanation for good frequency discrimination at $1000 \mathrm{~Hz}$, but relatively poor performance, compared to normal canaries, at 2000 and $4000 \mathrm{~Hz}$. Little effect of frequency might be observed in normal canaries, where spectral coding mechanisms may aid temporal coding mechanisms in the frequency region where phase locking declines.

The relationship between absolute threshold and frequency discrimination ability in BWC and non-BWC also indicates that spectral mechanisms are in play for higher frequencies and temporal mechanisms support frequency discrimination at lower frequencies. FDLs at $80 \mathrm{~dB}$ SPL are significantly correlated with absolute threshold in BWC and

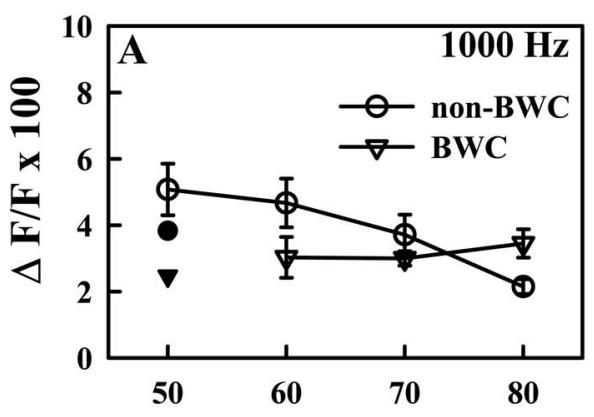

Sound Pressure Level (dB)

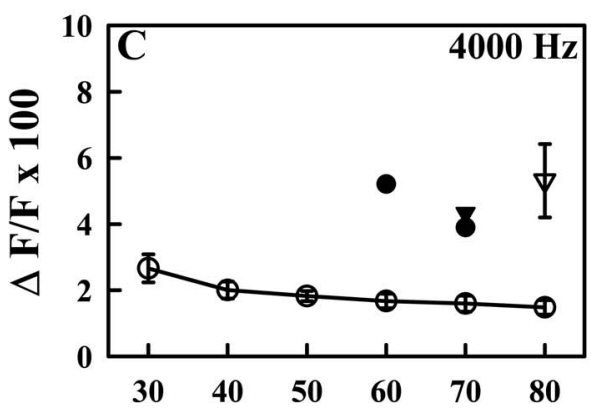

Sound Pressure Level (dB)

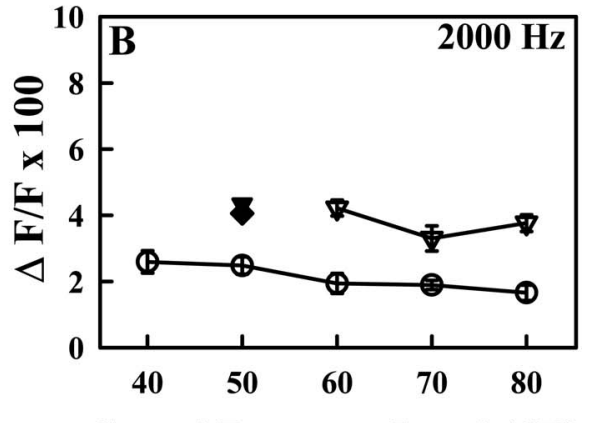

Sound Pressure Level (dB)

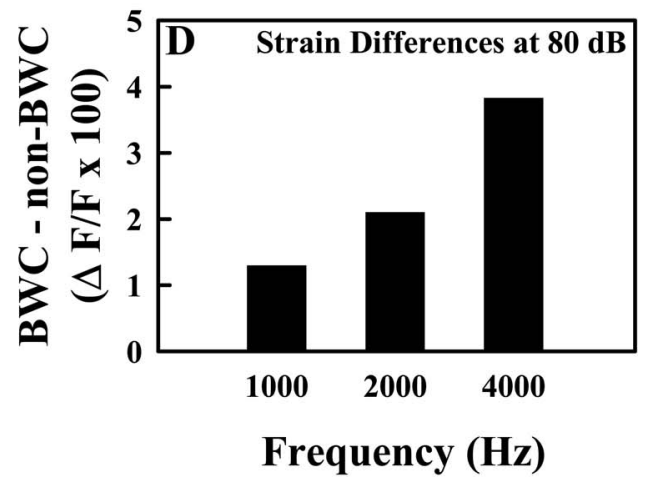

FIG. 2. Frequency difference limens for non-BWC (open circles; $n=4$ ) and BWC (open triangles; $n=4$ ) for (a) 1000, (b) 2000, and (c) $4000 \mathrm{~Hz}$ tones, and (d) strain differences at $80 \mathrm{~dB}$ SPL. Open symbols represent average data and closed symbols show individual data where average data were not available because not all subjects could be evaluated due to stimulus inaudibility. Error bars indicate standard error 


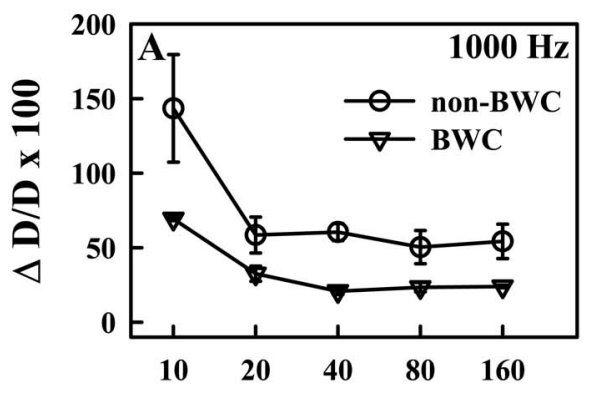

Background Duration (ms)

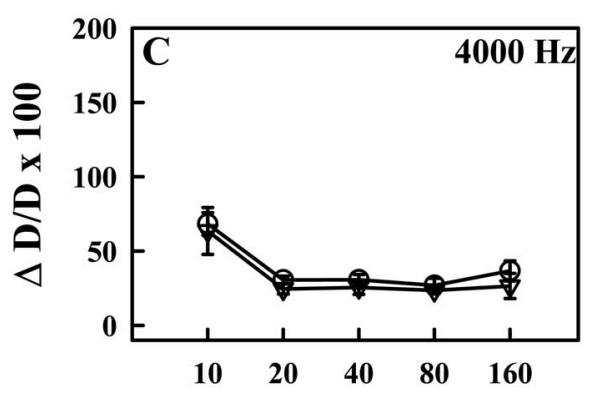

Background Duration (ms)

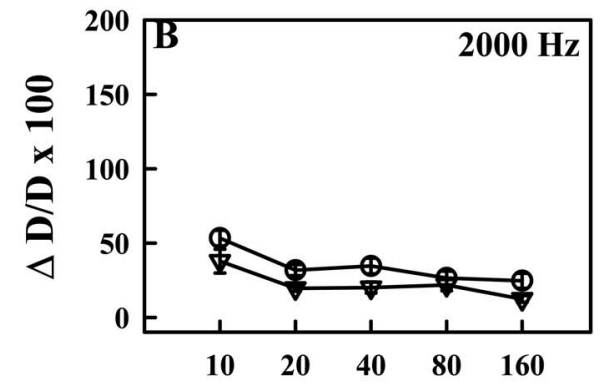

Background Duration (ms)

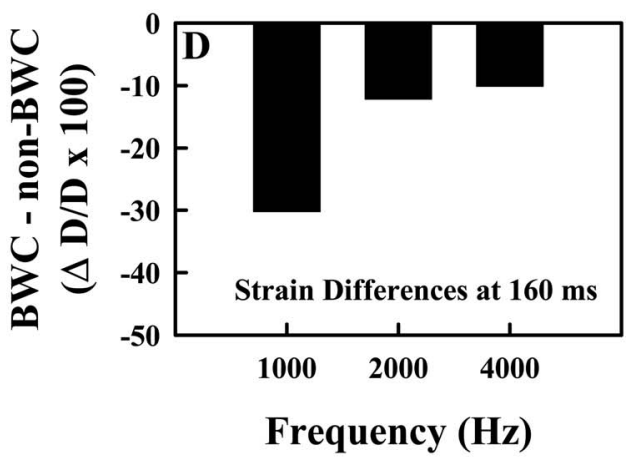

FIG. 3. Average duration difference limens for non-BWC (open circles; $n$ =4) and BWC (open triangles; $n=4$ ) for (a) 1000, (b) 2000, and (c) $4000 \mathrm{~Hz}$ tones, and (D) strain differences at $160 \mathrm{~ms}$. Error bars indicate standard error.
non-BWC when all reference frequencies are taken into account $\left(r^{2}=0.627, p<0.0001\right)$. However, a stronger correlation occurs between FDLs at $80 \mathrm{~dB}$ SPL and absolute threshold if the $1000 \mathrm{~Hz}$ data are excluded $\left(r^{2}=0.814, p<0.0001\right)$. Further, an analysis of the $1000 \mathrm{~Hz}$ data alone reveals no significant correlation between FDLs and absolute thresholds $\left(r^{2}=-0.021, p=0.732\right)$. These correlations, coupled with the fact that damage along the BWC basilar papilla is worse in the apex and midsection than in the basal region (Gleich et al., 1994; Weisleder and Park, 1994), suggest that temporal coding mechanisms are responsible for frequency discrimination at low frequencies in canaries.

Differences in frequency discrimination ability between BWC and non-BWC may be related to differences in vocalizations. The vocalizations of BWC contain most of their energy below $4000 \mathrm{~Hz}$ (Nottebohm and Nottebohm, 1978; Güttinger, 1985; Okanoya et al., 1990; Wright et al., 2004). In contrast, the vocalizations of non-BWC often have a significant amount of energy present at frequencies up to 6000 or $7000 \mathrm{~Hz}$ (Güttinger, 1985; Lohr et al., 2004). Reduced frequency discrimination ability at higher frequencies and good discrimination ability at lower frequencies might actually aid BWC in attending to strain-specific vocalizations.

\section{EXPERIMENT 2-DURATION DISCRIMINATION}

Despite the temporal stereotypy of most birdsong, few studies have investigated the ability to detect changes in sound duration in birds. Only two species have been tested. Budgerigars and starlings can detect about a 10-20\% increase in the duration of tones (Dooling and Haskell, 1978; Maier and Klump, 1990). Analysis of canary song structure reveals components that occur on several time scales (Güttinger, 1979; 1981, 1985). Singing bouts can last for many minutes, tours (repetitions of a single syllable) typically last several seconds, syllables range from approximately 50 to $300 \mathrm{~ms}$, and individual notes range from about 10 to $300 \mathrm{~ms}$. Sometimes, different canary syllables have similar frequency structure but differ in duration. Thus, it is of interest to determine duration discrimination ability in BWC and non-BWC. In this experiment, duration difference limens (DDLs) were measured for 1000, 2000, and $4000 \mathrm{~Hz}$ tones in BWC and non-BWC for a range of reference durations similar to the range of durations that are characteristic of canary song syllables.

\section{A. Methods: Stimuli and procedures}

Stimuli were 1000,2000 , and $4000 \mathrm{~Hz}$ pure tones with $5 \mathrm{~ms} \cos ^{2}$ rise/fall times. Background durations of 10, 20, 40, 80 , and $160 \mathrm{~ms}$ were used. Stimuli were presented at $80 \mathrm{~dB}$ SPL to ensure that the tones were at least $10 \mathrm{~dB}$ above absolute thresholds for BWC at all frequencies. Thresholds for detecting increases in duration were measured in 4 BWC and 4 non-BWC. Target tones were presented in increments of 10 or $20 \%$ of the background durations, depending on the bird's performance. The average false alarm rate was $2.7 \%$ for nonBWC and $3.1 \%$ for BWC. Based on the same criteria used in Experiment 1, $2 \%$ of the data from non-BWC were discarded, and $4 \%$ of the data from BWC were discarded.

\section{B. Results and discussion}

DDLs for (a) 1000, (b) 2000, and (c) $4000 \mathrm{~Hz}$ tones for BWC and non-BWC are shown in Fig. 3. Strain differences (BWC DDL-non-BWC DDL) for the $160 \mathrm{~ms}$ tone are shown in Fig. 3(d). Non-BWC were able to detect an increase of approximately $25-30 \%$ in duration for stimuli that were longer than $10 \mathrm{~ms}$ at 2000 and $4000 \mathrm{~Hz}$, and 50-60\% at $1000 \mathrm{~Hz}$. These thresholds are somewhat larger than DDLs reported in other bird species (Dooling and Haskell, 
1978; Maier and Klump, 1990). BWC were able to detect increases of $20-30 \%$ in duration above $10 \mathrm{~ms}$ for all frequencies. DDLs increased at the shortest duration tested (10 ms) for both non-BWC (50-140\%) and BWC (40-70\%) and varied more among individual birds than at other durations. Budgerigars and starlings also show increased DDLs for very short durations (Dooling and Haskell, 1978; Maier and Klump, 1990). A strain $\times$ frequency $\times$ duration mixed factor ANOVA revealed significant effects of strain $[F(1,6)$ $=26.897, p=0.002]$ and duration $[F(4,24)=28.128, p$ $<0.0001]$, and significant interactions between duration and strain $[F(4,24)=5.903, p=0.002]$ and between duration and frequency $[F(8,48)=24.752, p<0.0001]$. The significant interaction between duration and strain indicates that there may be at least some differences between BWC and nonBWC for certain reference durations. The significant interaction between duration and frequency also indicates that duration discrimination ability is not completely independent of frequency in these birds. There was not a significant main effect of frequency, and no other interactions were significant.

These results show that the inner ear abnormalities in BWC have no detrimental effect on duration discrimination. Considering that the stimulus presentation level was $80 \mathrm{~dB}$ SPL, BWC were listening at a reduced sensation level (SL) compared to non-BWC. However, this reduced audibility of the stimuli did not have a negative effect on performance. Surprisingly, BWC were actually slightly better than nonBWC at discriminating changes in the duration of a $1000 \mathrm{~Hz}$ tone, though the effect is not statistically significant (i.e., there was no significant strain by frequency interaction). Differences in DDLs as a function of frequency have not been reported in humans or other nonhuman animals.

\section{EXPERIMENT 3-INTENSITY DISCRIMINATION}

Most avian species can detect intensity changes as small as 1-4 dB (reviewed in Dooling et al., 2000). This ability is assumed to be based on the perceived loudness of sounds. Clearly, the dynamic range of the BWC auditory system is restricted at higher frequencies as a consequence of the hearing loss. However, it is unknown how other aspects of the perception of sound intensity are affected in BWC.

In an earlier experiment, intensity difference limens (IDLs) for continuous broadband noise were measured in BWC (Okanoya and Dooling, 1985). IDLs ranged from approximately 2.9 to $1 \mathrm{~dB}$ for noise levels between 60 and $90 \mathrm{~dB}$ SPL. Between 70 and $90 \mathrm{~dB}$ SPL, IDLs changed very little with increasing level. This result is consistent with predictions from Weber's law and with reported IDLs for noise in budgerigars (Dooling and Searcy, 1981). Performance in BWC was worse at lower sound levels presumably because of the inaudibility of high frequency noise components. To test whether discrimination of intensity changes in pure tones are also affected in BWC, IDLs were measured as a function of frequency and level in BWC and non-BWC. Birds were tested at equal SLs in order to make comparisons at points that were an equivalent amount above absolute threshold across the dynamic range of each strain.

\section{A. Methods: Stimuli and procedures}

Stimuli were 1000,2000 , and $4000 \mathrm{~Hz}$ pure tones with durations of $400 \mathrm{~ms}$ with $20 \mathrm{~ms} \cos ^{2}$ rise/fall times. Target tones were presented with an increment size of 1 or $2 \mathrm{~dB}$, depending on the bird's performance. Thresholds for the smallest detectable increase in intensity were measured in 4 BWC and 4 non-BWC at levels of 10, 20, 30, and $40 \mathrm{~dB}$ SL. It was not possible to test BWC at all SLs for all frequencies due to the high levels of sound necessary to determine thresholds. The average false alarm rate was $2.5 \%$ for nonBWC and 3.3\% for BWC. Based on the same criteria used in Experiment $1,2 \%$ of the data from non-BWC were discarded, and $4 \%$ of the data from BWC were discarded.

\section{B. Results and discussion}

IDLs for BWC and non-BWC at equal SLs are plotted in Fig. 4 for (a) 1000, (b) 2000, and (c) $4000 \mathrm{~Hz}$. Individual data points are plotted where no average data were computed because not all birds could perform the task at all SLs. IDLs for non-BWC ranged from approximately 3 to $6 \mathrm{~dB}$. Strain differences (BWC IDL-non-BWC IDL) for the $10 \mathrm{~dB}$ SL condition are shown in Fig. 4(d). Overall, BWC had somewhat lower IDLs than non-BWC, but IDLs decreased with increasing level for both strains. The range of IDLs reported here for non-BWC is consistent with those reported for pure tones in other bird species (Dooling and Saunders, 1975; Dooling and Searcy, 1979; Hienz et al., 1980; Klump and Baur, 1990; Wright et al., 2003). As intensity difference limens in BWC and non-BWC expressed in $\mathrm{dB}$ did not remain constant across testing levels, intensity discrimination of pure tones in both BWC and non-BWC deviates from Weber's law. This result is also consistent with intensity discrimination studies in other bird species and other vertebrates (Fay, 1988), in which IDLs to noise follow Weber's law and IDLs to tones do not.

Because BWC were not tested at all of the levels at each frequency that non-BWC were tested on, it was not possible to perform an ANOVA on the entire set of data. Thus, a mixed factor ANOVA (strain $\times$ frequency) was conducted on the IDLs for the $10 \mathrm{~dB}$ SL condition only. This condition was chosen because all animals were tested at $10 \mathrm{~dB}$ SL at all frequencies. There was a significant effect of strain $[F(1,6)=36.865, p=0.001]$, and a marginally significant effect of frequency $[F(2,12)=3.909, p=0.049]$. The interaction between strain and frequency was not significant.

Although IDLs were consistently smaller in BWC than in non-BWC at $10 \mathrm{~dB}$ SL, this finding may reflect the higher SPL levels used in testing BWC and not an enhanced discrimination ability in the hearing-impaired birds. At the points where BWC and non-BWC can be compared at equivalent SPLs, BWC performed about as well as nonBWC. This is consistent with earlier reports of intensity discrimination in hearing-impaired humans, who often perform better than listeners with normal hearing at equal SLs, but not at equal SPLs (Turner et al., 1989; Glasberg and Moore, 1989). Despite the significant amount of missing and damaged hair cells along and across the BWC basilar papilla and the reduced number of auditory nerve fibers, BWC must ob- 


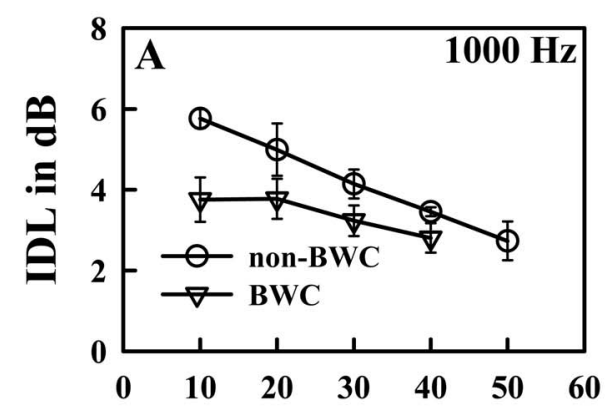

Sensation Level (dB)

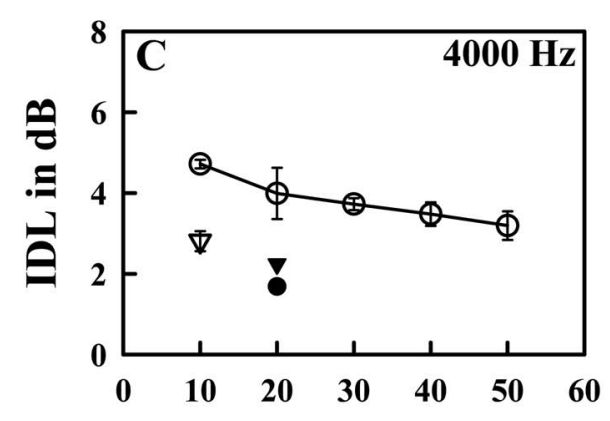

Sensation Level (dB)

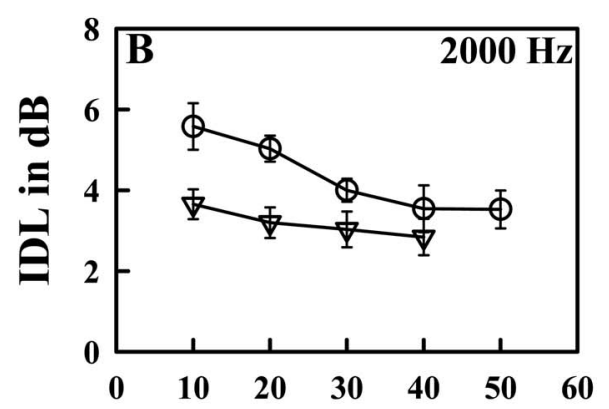

Sensation Level (dB)

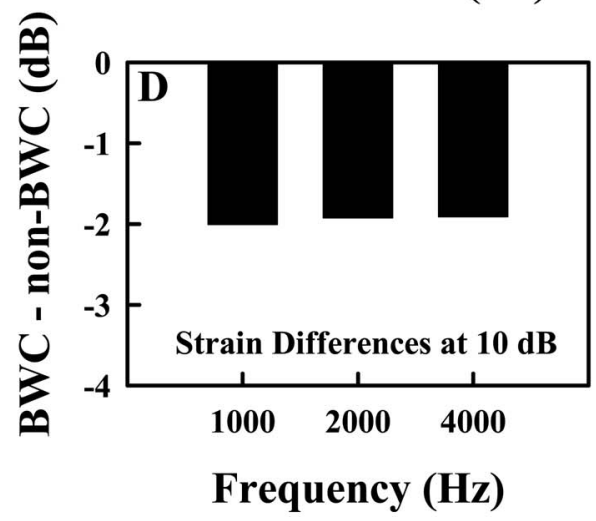

FIG. 4. Intensity difference limens for non-BWC (open circles; $n=4$ ) and BWC (open triangles; $n=4$ ) for (a) 1000, (b) 2000, and (c) $4000 \mathrm{~Hz}$ tones, (d) and strain differences at $10 \mathrm{~dB}$ SL. Open symbols represent average data. Closed symbols show individual data where average data were not available. Error bars indicate standard error. viously have enough afferent input to encode sound intensity sufficiently to produce normal behavioral results. This is consistent with Viemeister (1988) who suggested that changes in firing rate in a small number of neurons can account for intensity discrimination abilities in mammals.

\section{EXPERIMENT 4-TEMPORAL INTEGRATION}

Temporal integration refers to the auditory system's ability to integrate acoustic energy over time, and is reflected in the relationship between the duration of a sound and the threshold for detection of that sound (Hughes, 1946). Detection thresholds decrease exponentially as the duration of a sound increases from a few milliseconds to several hundred milliseconds. No further significant decreases in threshold are observed beyond the asymptotic value. The rate of threshold improvement with increasing duration is typically 2-3 dB/doubling of duration (Saunders and Salvi, 1993). Earlier studies of temporal integration in birds indicate about a 10-20 dB threshold improvement with increasing stimulus duration (Dooling, 1979; Dooling and Searcy, 1985; Klump and Maier, 1990; Saunders and Salvi, 1993).

Temporal integration in BWC and non-BWC was measured for several tone frequencies. Saunders et al. (1995) demonstrated that temporal integration is reduced in chickens with temporary hearing loss resulting from hair cell damage. Similarly, BWC were expected to show smaller changes in threshold with increasing duration compared to non-BWC.

\section{A. Methods: Stimuli and procedures}

Pure tones of 1000, 2000, and $4000 \mathrm{~Hz}$ with durations of $5,10,20,40,80,160,240,320$, and $480 \mathrm{~ms}$ and $\cos ^{2}$ rise/ fall times of $2 \mathrm{~ms}$ were used as target stimuli. Thresholds for detecting tones of different durations presented in quiet were measured in 4 non-BWC and 4 BWC. Tones were presented in increments of $5 \mathrm{~dB}$ within a block of 10 trials. The average false alarm rate was $3.0 \%$ for non-BWC and $2.9 \%$ for BWC. Using the same criteria as in the previous experiments, $13 \%$ of the data from non-BWC were discarded, and $5 \%$ of the data from BWC were discarded. The amount of discarded data is somewhat high for the non-BWC because the birds initially had very unstable behavior when detecting the tones with the smallest durations.

\section{B. Results and discussion}

To facilitate comparisons of the amount of threshold change in non-BWC and BWC, relative thresholds (threshold at duration $x$-threshold at longest duration) were calculated for individual birds at each frequency. Average relative thresholds as a function of tone duration for (A) 1000, (B) 2000, and (C) $4000 \mathrm{~Hz}$ are shown in Fig. 5 for non-BWC and BWC. Strain differences in the amount of threshold improvement between 5 and $480 \mathrm{~ms}$ are shown in Fig. 5(d). Threshold-by-duration functions were shallower for BWC than for non-BWC at all durations tested. Non-BWC showed a decrease in threshold of about 10 to $15 \mathrm{~dB}$ with increasing stimulus duration for all frequencies. This rate of threshold change over the range of durations tested here of $1.5-2.5 \mathrm{~dB} /$ doubling of duration is generally consistent with reports in other species of birds (Dooling, 1979; Dooling and Searcy, 1985; Klump and Maier, 1990; Saunders and Salvi, 1993).

Relative thresholds improved by about $7 \mathrm{~dB}$ with increasing duration at $2000 \mathrm{~Hz}$ in BWC, decreasing at a rate of about $1.2 \mathrm{~dB} /$ doubling, but showed less than $5 \mathrm{~dB}$ of improvement at 1000 and $4000 \mathrm{~Hz}$ (less than $1 \mathrm{~dB} /$ doubling threshold improvement). The amount of temporal integration 

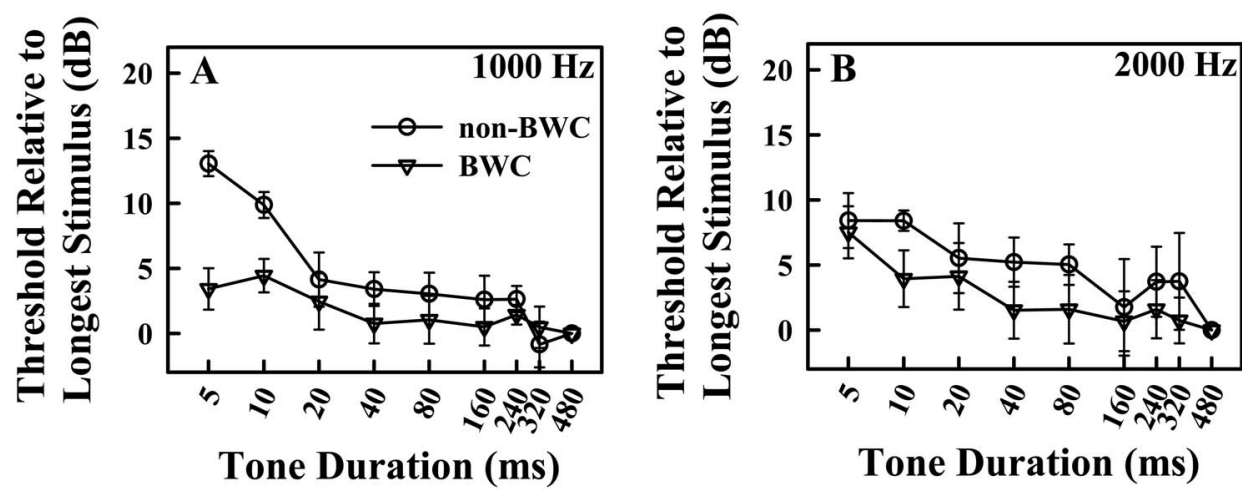

Tone Duration (ms)

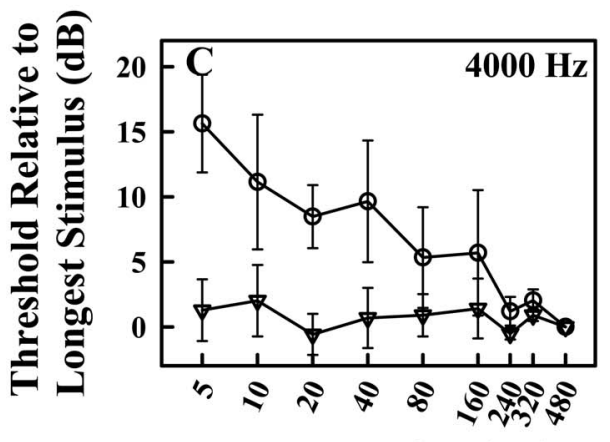

Tone Duration (ms)

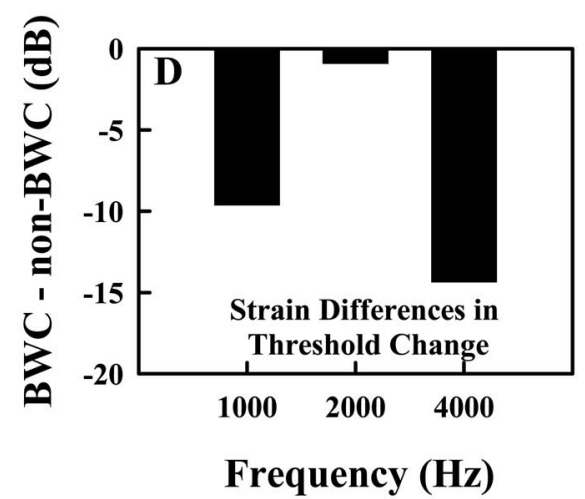

FIG. 5. Average absolute thresholds for pure tones as a function of duration for non-BWC (open circles; $n=4$ ) and BWC (open triangles; $n=4$ ) for (a) 1000, (b) 2000, and (c) $4000 \mathrm{~Hz}$, and (d) strain differences in threshold improvement. Error bars indicate standard error. in BWC is consistent with the amount of temporal integration reported in chickens with temporary hearing loss (Saunders et al., 1995). A strain $\times$ frequency $\times$ duration mixed factor ANOVA revealed significant effects of duration $[F(8,48)=28.409, p<0.0001]$ and strain $[F(1,6)$ $=14.099, p=0.009]$, and significant interactions of duration and strain $[F(8,48)=7.264, p<0.0001]$ and frequency, duration, and strain $[F(16,96)=2.017, p=0.019]$. These interactions indicate that duration-dependent changes in threshold showed differing dependence on frequency in BWC and nonBWC. No other interactions were significant. There was no significant effect of frequency, indicating that temporal integration does not change systematically with frequency. Two stimulus durations, 5 and $240 \mathrm{~ms}$, were chosen for post hoc comparisons using the Bonferroni method. Relative thresholds at $5 \mathrm{~ms}$ were higher in non-BWC than in BWC at $1000 \mathrm{~Hz} \quad[t(6)=5.166, p=0.002]$ and $4000 \mathrm{~Hz} \quad[t(6)$ $=3.905, p=0.008]$, but not at $2000 \mathrm{~Hz}$. Relative thresholds at $240 \mathrm{~ms}$ were not significantly different between non-BWC and BWC at any frequency. Thus, threshold improved more with increasing duration (indicating increased temporal integration) for non-BWC than BWC at 1000 and $4000 \mathrm{~Hz}$, but not at $2000 \mathrm{~Hz}$. The amount of threshold improvement at $2000 \mathrm{~Hz}$ was similar in BWC and non-BWC. The audiogram shows the best sensitivity at about $2000 \mathrm{~Hz}$ in BWC. It is possible that the portion of the stimulus which is effective in driving the hair cells is most unaffected by damage in this region, thereby supporting good temporal integration (Neubauer and Heil, 2004).

Smaller changes in threshold with increasing stimulus duration have typically been attributed to reduced temporal integration resulting from reduced peripheral compression in hearing-impaired human listeners (Gengel and Watson, 1971; Pedersen and Eberling, 1973; Elliott, 1975; Chung, 1981;
Hall and Fernandes, 1983; Carlyon et al., 1990) and cats with experimentally induced hearing loss (Solecki and Gerken, 1990). However, a new analysis of the data from cats indicates that the reduction in threshold change associated with hearing loss is actually due to changes in the effective portion of the stimulus rather than changes in the temporal integration mechanism (Neubauer and Heil, 2004). That is, not only is there a reduction in sensitivity with hearing loss, but also an elevation in the baseline above which sound pressure is effective in exciting the auditory system. A similar explanation may hold for the smaller threshold change with increasing stimulus duration observed in BWC.

\section{EXPERIMENT 5-GAP DETECTION}

Although measures of temporal integration describe how an organism combines auditory information over a period of time, these measures do not describe the ability to resolve temporal fluctuations in sounds. A simple and convenient measure of temporal resolution of the auditory system can be obtained by measuring thresholds for detecting temporal gaps, or brief silent periods, in noise. Starlings, zebra finches, budgerigars, and barn owls can detect about a 2-3 ms gap in noise with levels exceeding $20 \mathrm{~dB}$ SL (Okanoya and Dooling, 1990; Klump and Maier, 1989; Klump et al., 1998). Gap detection thresholds (GDTs) for birds increase at lower noise levels (Okanoya and Dooling, 1990; Klump and Maier, 1989; Klump et al., 1998). Okanoya and Dooling (1990) found that a reciprocal relationship between resolution of gaps in noise and spectral resolution exists in the zebra finch. Thresholds for gaps in octave-band noise were easily predicted from critical ratios in zebra finches, where larger GDTs corresponded to smaller critical ratio values. These results are consistent with the time/ 
frequency resolution trade-off described in theories of the filtering properties of the mammalian ear (Duifhuis, 1973; de Boer, 1985). A similar relationship was not found in budgerigars, probably due to their unusual critical ratio function (Okanoya and Dooling, 1990). These species differences in the relationship between frequency selectivity and temporal resolution may reflect more general differences between songbirds and parrots.

In the present experiment, thresholds for detecting gaps in broadband noise-bursts were measured in BWC and nonBWC. If an inverse relationship between frequency selectivity and temporal resolution exists in canaries as it does in zebra finches, then BWC should have smaller GDTs than non-BWC provided all components of the stimuli are clearly audible. However, if temporal coding of stimuli is compromised in BWC, then they should show larger GDTs than non-BWC. GDTs were expected to decrease with increasing sound level in both strains.

\section{A. Methods: Stimuli and procedures}

Background stimuli were $300 \mathrm{~ms}$ bursts of Gaussian noise with $5 \mathrm{~ms} \cos ^{2}$ rise/fall times, sampled at $40 \mathrm{kHz}$ and lowpass filtered at $15 \mathrm{kHz}$. The target sounds were noisebursts with silent gaps of different durations centered within the noise-burst. Rise/fall times of the noise on either side of the gap were essentially instantaneous (i.e., the minimum time specified by the stimulus generation software). The total duration of the target sounds, including gaps and noisebursts, was kept at a constant $300 \mathrm{~ms}$. Thresholds were measured in 4 BWC and 4 non-BWC.

Absolute thresholds for noise-bursts were measured to establish audibility levels for noise-bursts. GDTs were measured by randomly alternating target sounds (noise-bursts containing gaps) with repeating background noise-bursts without gaps. GDTs were measured for noise-bursts with levels of 60, 65, 70, and $75 \mathrm{~dB}$ SPL in BWC and 40, 50, 60, 65,70 , and $75 \mathrm{~dB}$ SPL in non-BWC. Noise-bursts with gaps of different durations were presented with a step size of 1 or $2 \mathrm{~ms}$, depending on the birds' behavior. The average false alarm rate was $2.6 \%$ for non-BWC and $4.0 \%$ for BWC. NonBWC initially showed unstable behavior at the lower sound levels tested. Based on criteria used in the previous experiments, $17 \%$ of the data from non-BWC were discarded, and $7 \%$ of the data from BWC were discarded.

\section{B. Results and discussion}

Average absolute thresholds for noise-bursts were significantly lower for non-BWC (mean $=22.08 \mathrm{~dB}$ SPL, SD =3.91) than for BWC (mean=47.23 dB SPL, SD=5.89) $[t(6)=-7.089, p<0.0001]$. This difference in thresholds for noise-bursts between non-BWC and BWC is comparable to differences in pure tone thresholds between the two strains for frequencies above $2000 \mathrm{~Hz}$. Presumably, thresholds for noise-bursts are higher in BWC than in non-BWC due to the inaudibility of the high frequency components of the noise.

Average gap detection thresholds for BWC and nonBWC are shown in Fig. 6. Thresholds increased from $3.62 \mathrm{~ms}$ at $75 \mathrm{~dB}$ SPL to $6.49 \mathrm{~ms}$ at $40 \mathrm{~dB}$ SPL for non-

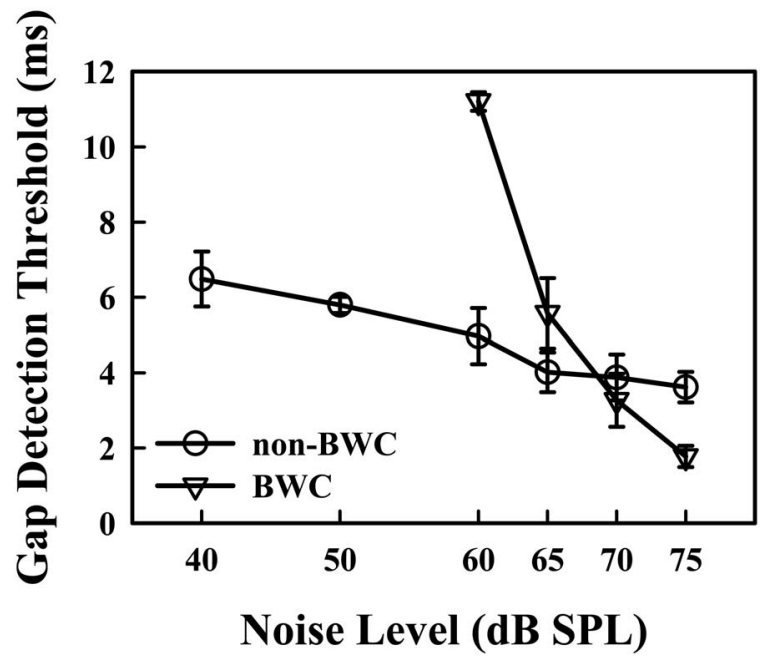

FIG. 6. Average gap detection thresholds as a function of sound pressure level for BWC (open circles; $n=4$ ) and non-BWC (open triangles; $n=4$ ). Error bars indicate standard error.

BWC. These GDTs are within the range of those reported in other species of birds (Klump and Maier, 1989; Okanoya and Dooling, 1990; Klump et al., 1998). Thresholds for BWC increased from $1.78 \mathrm{~ms}$ at $75 \mathrm{~dB}$ SPL to $11.21 \mathrm{~ms}$ at $60 \mathrm{~dB}$ SPL. BWC were not tested at lower levels due to audibility constraints. In the range of 60 to $75 \mathrm{~dB}$ SPL, BWC showed a much larger change as a function of level than non-BWC.

A strain $\times$ level mixed factor ANOVA revealed significant effects of strain $[F(1,16)=224.464, p<0.0001]$ and level $[F(3,18)=62.909, p<0.0001]$, and a significant interaction between strain and level $[F(3,18)=48.023, p$ $<0.0001]$. Post hoc analyses using the Bonferroni method showed that GDTs for BWC were not significantly different from GDTs for non-BWC at 65 and $70 \mathrm{~dB}$ SPL. GDTs for BWC were larger than GDTs for non-BWC at $60 \mathrm{~dB}$ SPL $[t(4)=8.875, p<0.05]$, and were lower than for non-BWC at $75 \mathrm{~dB}$ SPL $[t(4)=-3.851, p<0.05]$.

The sharp decrease in resolution of gaps between 75 and $60 \mathrm{~dB}$ SPL in BWC may be related to the low audibility of high frequency components of the noise-bursts at 60 and $65 \mathrm{~dB}$. Recall that thresholds for noise-bursts were approximately $25 \mathrm{~dB}$ lower in non-BWC than in BWC. Thus, $60 \mathrm{~dB}$ SPL is approximately $35 \mathrm{~dB}$ SL in non-BWC, but only $10 \mathrm{~dB}$ SL in BWC. As the higher frequency components become less audible, BWC performance decreases.

The superior temporal resolution at higher sound levels in BWC may be related to the wider bandwidth of auditory filters in the area of hearing loss. An earlier experiment showed impaired frequency resolution at high frequencies in BWC (Lauer and Dooling, 2002; Lauer et al. 2002, 2006). The wider auditory filters associated with poor frequency resolution may result in less smoothing of the input wave form over time, thus preserving more of the fine details of the signal that aid gap detection. Additionally, wider filters have less ringing than narrow filters. Ringing may obscure the abrupt offset of the noise when a gap occurs, thereby increasing GDTs for non-BWC. 
VIII. EXPERIMENT 6-DISCRIMINATION OF CHANGES IN TIME-REVERSED HARMONIC COMPLEXES

The vocalizations of birds can be quite temporally complex, with both slow envelope fluctuations and fast withinperiod fluctuations. Canary syllables and calls often include upward or downward frequency sweeps. The majority of studies of temporal resolution in birds have focused on resolution of slow overall changes in the envelope of sounds. Recently, Dooling et al. (2002) and Lohr et al. (2006) presented evidence that birds are superior to humans when envelope and frequency cues are removed and discrimination of sounds must rely on cues in the temporal fine structure (within-period temporal fluctuations).

The differences in resolution of within-period temporal changes between birds and humans are thought to be related in part to the width of the auditory filters. Broader auditory filters should lead to better within-channel temporal resolution in a linear system because there is better preservation of phase relationships as more components fall within one channel (Duifhuis, 1973; de Boer, 1985). Behavioral estimates of auditory filter bandwidth suggest that birds generally have broader filters than humans (reviewed in Dooling et al., 2000). However, tuning curves of some auditory nerve fibers in birds are more narrowly tuned than in mammals (reviewed in Gleich and Manley, 2000). Thus, the relationship between temporal acuity and peripheral auditory filtering mechanisms remains unclear.

Experiment 5 demonstrated that BWC are actually better than non-BWC at detecting changes in the envelope of sounds under certain conditions. The present experiment addresses the question of whether or not resolution of fast within-period temporal changes is also enhanced in BWC. The ability to discriminate changes in temporal fine structure was measured in BWC and non-BWC using procedures identical to those of Dooling et al. (2002).

\section{A. Methods: Stimuli and procedures}

The stimuli have been described in detail elsewhere (Dooling et al., 2002). Harmonic complexes were composed of equal amplitude components with component starting phases selected according to the Schroeder (1970) algorithm $\left[\theta_{n}= \pm \pi n(n+1) / N\right.$, where $\theta=$ component starting phase, $n$ $=$ component number within the complex, and $N=$ total number of components]. Reversing the sign of the phase algorithm results in two wave forms that are the reverse of each other in time. Complexes with fundamental frequencies of $150,200,300,400,600,800$, and $1000 \mathrm{~Hz}$ were created. The periods of these stimuli ranged from 1 to $6.67 \mathrm{~ms}$. The wave forms were $260 \mathrm{~ms}$ in duration, with $20 \mathrm{~ms} \cos ^{2}$ onset/offset ramps. Stimuli were presented at $80 \mathrm{~dB}$ SPL. Sections of negative and positive-phase stimuli with a fundamental frequency of $200 \mathrm{~Hz}$ are shown in Fig. 7(a).

Three BWC were tested using procedures identical to those of Dooling et al. (2002). The data from BWC were compared to data from 3 non-BWC reported by Dooling et al. (2002). Birds were trained to discriminate between negative-phase and positive-phase wave forms at each fundamental frequency. As birds required extra training when

\section{F0 $=200 \mathrm{~Hz}$}

A
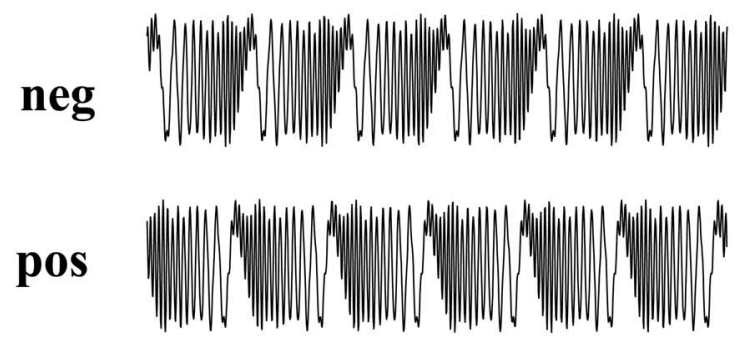

$5 \mathrm{~ms}$
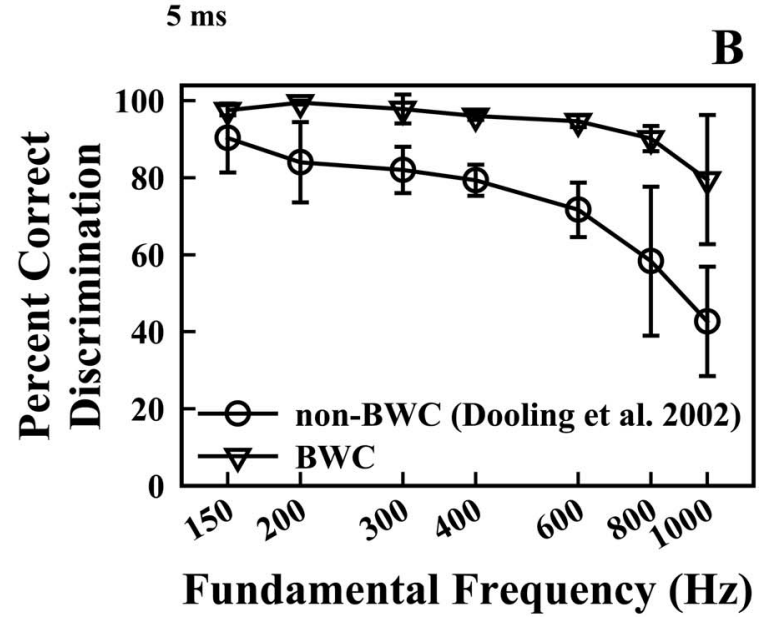

FIG. 7. (A) Examples of harmonic complexes used as stimuli in Experiment 6. Complexes were constructed by summing equal amplitude components with starting phases selected according to the Schroeder algorithm. Complexes with higher fundamental frequencies have shorter period durations. (B) Average percent correct discriminations of harmonic complexes for nonBWC (open circles; $n=3$; Dooling et al., 2002) and BWC (open triangles; $n=3$ ). Error bars indicate standard error.

switching between negative-phase and positive-phase background sounds, all fundamental frequencies were tested for a given phase selection (negative or positive) before switching to the opposite phase selection. Whether a bird began with the negative-phase or the positive-phase background sounds was chosen randomly.

Behavior was considered stable if the percent correct for a given target did not change more than $10 \%$ within the last two 100-trial blocks. If the bird's percent correct remained at $100 \%$ for the first two blocks of 100 trials, the bird was not run on more trials for that condition. Percent correct discrimination values for each experimental condition were taken as the mean percent correct over the last 200 trials run. The average false alarm rate was $4.5 \%$ for BWC. Data from sessions with false alarm rates larger than $18 \%$ were excluded from analysis. Seven percent of the data were discarded.

\section{B. Results and discussion}

Figure 7(b) shows percent correct discriminations for harmonic complexes with different fundamental frequencies for BWC along with data from non-BWC (from Dooling et al., 2002). Average BWC discrimination ability was high ( $80 \%$ correct or better) for complexes with fundamental fre- 
quencies up to $1000 \mathrm{~Hz}$, whereas non-BWC discrimination performance decreased to less than $60 \%$ correct for complexes with fundamental frequencies of 800 and $1000 \mathrm{~Hz}$. BWC were able to perform above $80 \%$ correct even for stimuli with periods as short as $1.0 \mathrm{~ms}$. This is well beyond the human limit, which falls at about $300-400 \mathrm{~Hz}$ (Dooling et al., 2002). Overall, percent correct discriminations for BWC were almost as high as those reported for zebra finches and were slightly higher than in budgerigars (Dooling et al., 2002).

BWC showed better performance than non-BWC at most fundamental frequencies; however a mixed factor (strain $\times$ fundamental frequency) ANOVA showed that the main effect of strain was not significant. The lack of a significant main effect of strain is probably due to similar performance between non-BWC and BWC at some fundamental frequencies. There was a significant effect of fundamental frequency $[F(6,24)=16.056, p<0.0001]$ and a significant interaction between fundamental frequency and strain $[F(6,24)=2.667, p=0.040]$. Estimates of effect sizes were calculated in the absence of a significant effect of strain. Large effects occurred for fundamental frequency $\left[\eta^{2}\right.$ $=0.801]$ and strain $\left[\eta^{2}=0.636\right]$. A moderate effect size was found for the interaction between strain and fundamental frequency $\left[\eta^{2}=0.40\right]$. Post hoc comparisons using the Bonferroni method showed that BWC had higher percent correct discriminations only for complexes with fundamental frequencies of $300 \mathrm{~Hz}[t(4)=3.354, p<0.05]$ and $600 \mathrm{~Hz}$ $[t(4)=3.137, p<0.05]$. The excellent resolution of fast temporal changes seen in BWC may be attributed in part to wider filter bandwidths at higher frequencies. Wider filters allow more components of the harmonic complexes to fall within one channel, thereby preserving more of the phase relationships between components than in narrower filters.

\section{GENERAL DISCUSSION}

This study examined in detail the hearing abilities in an animal with early-onset hereditary high-frequency hearing loss bred for its unique low-pitched vocalizations - the Belgian Waterslager canary. Remarkably, only some aspects of hearing investigated in this study were impaired, despite the extensive damage that occurs along the BWC basilar papilla. Frequency discrimination was quite good at $1000 \mathrm{~Hz}$ in BWC; however, discrimination of changes in higher frequencies was worse in BWC than in non-BWC. Duration discrimination was also similar in BWC and non-BWC overall, but was slightly better in BWC at $1000 \mathrm{~Hz}$. Intensity discrimination was also not adversely affected in BWC. Temporal integration was reduced at 1000 and $4000 \mathrm{~Hz}$ but not at $2000 \mathrm{~Hz}$ in BWC, gap detection was especially good in BWC provided the high frequency components of the stimuli were clearly audible, and discrimination of fast within-period temporal changes was also somewhat better than normal in BWC. Taken all together, these results seem to point to deficits that are mostly related to impaired spectral resolution that typically results from sensorineural hearing loss, and an accompanying enhancement in temporal processing.
The auditory sensitivities that are clearly abnormal in this population are absolute thresholds, frequency resolution and frequency discrimination at high frequencies (where temporal processing may suffer from reductions in phase locking in the auditory nerve), and temporal integration. The latter may be impaired because of loss of effective bandwidth due to reduced audibility, also a spectral effect. Interestingly, the enhancement of temporal resolution, which may have had a role in most if not all of the normal or supernormal results reported here, occurred in spite of the fact that BWC show some abnormalities in the auditory brainstem nuclei involved in temporal processing. Nucleus magnocellularis and nucleus laminaris show normal cell number and organization in adult birds; however, both have reduced volumes attributed to smaller cell size (Kubke et al., 2002). Presumably, the smaller cell size is a result of the progressive reduction of auditory input from an early age. It is possible that either the reduced volume is simply not enough to have a profound impact on temporal resolution, or that some subcellular mechanism such as an increased thickness of the postsynaptic densities compensates for the reduction in cell size.

The results from these experiments show that there are significant perceptual consequences of the early-onset hearing loss in BWC other than elevated pure tone thresholds. Still, BWC hear remarkably well given the extensive degree of basilar papillar damage. The unique perceptual profile in BWC can, in some ways, be viewed as a compensation for loss of high-frequency hearing. Although these birds have poor detection and resolution of high frequency sounds, they have excellent temporal resolution and intensity discrimination. In addition to enhanced temporal resolution, which may be a serendipitous byproduct of hair cell damage, BWC may have developed more central compensatory mechanisms that promote processing of strain-specific sounds in the absence of reliable high frequency cues. This success is even more remarkable if one considers that the BWC are actually listening at a lower sensation level than non-BWC in their everyday environment.

The link between perceptual abilities and vocal characteristics in BWC highlights the uniqueness of this animal system. These birds show a unique pattern of perceptual abilities that may enhance their ability to learn and produce strain-specific vocalizations. This model is exceptional in that it is the only animal in which we can investigate the link between genetics, auditory system structural abnormalities, vocal learning, vocal production, hair cell regeneration, and hearing abilities. The close correspondence between auditory perception and vocal characteristics in BWC suggests that the auditory pathology is a product of artificial selection. As breeders mated birds with desirable low-pitched song elements, they may have inadvertently selected for auditory system abnormalities. In essence, breeders may have artificially produced a specialization in BWC over several hundred years.

The BWC model has a unique potential to further our understanding of the evolution of vocal learning and production and the role of genetics in hearing and auditory pathology. We now have an extensive behavioral assay to comple- 
ment the many studies describing the auditory pathology in BWC. To our knowledge, this is the most comprehensive psychophysical exploration in an animal with hereditary hearing loss. Future studies should investigate the specific genes responsible for the hair cell abnormalities, the relationships among basilar papilla microstructure, hearing abilities, and the physiological response of the auditory system, and the role of genetic predispositions in song learning in BWC.

\section{ACKNOWLEDGMENTS}

This work was supported by NIH Grant No. DC-01372 to RJD, Grant No. DC-005450 to AML, Grant No. DC00626 to MRL, and Grant No. DC-04664. Portions of this work were presented at the 2003 and 2004 Midwinter Meeting of the Association for Research in Otolaryngology, Daytona Beach, FL and the 147th Meeting of the Acoustical Society of America.

Brittan-Powell, E. F., Dooling, R., Wright, T., Mundinger, P., and Ryals, B. (2002). "Development of auditory sensitivity in Belgian Waterslager (BWC) canaries," Assoc. Res. Otolaryngol. St. Petersburg, FL.

Carlyon, R. P., Buus, S., and Florentine, M. (1990). "Temporal integration of tone pulses by normal and by cochlearly impaired listeners," J. Acoust. Soc. Am. 87, 260-268.

Chung, D. Y. (1981). "Masking, temporal integration, and sensorineual hearing loss," J. Speech Hear. Res. 24, 514-520.

de Boer, E. (1985). "Auditory time constants: A paradox?" Time Resolution in the Auditory System, edited by A. Michelson (Springer, Berlin), pp. 141-158.

Dooling, R. J. (1979). "Temporal summation of pure tones in birds," J. Acoust. Soc. Am. 65, 1058-1060.

Dooling, R. J., and Haskell, R. J. (1978). "Auditory duration discrimination in the parakeet (Melopsittacus undulatus)," J. Acoust. Soc. Am. 63, 16401642 .

Dooling, R. J., Leek, M. R., Gleich, O., and Dent, M. L. (2002). "Auditory temporal resolution in birds: Discrimination of harmonic complexes," J. Acoust. Soc. Am. 112, 748-759.

Dooling, R. J., Lohr, B., and Dent, M. L. (2000). "Hearing in birds and reptiles," Comparative Hearing: Birds and Reptiles, edited by R. J. Dooling, R. R. Fay, and A. N. Popper (Springer, Berlin), pp. 197-248.

Dooling, R. J., and Okanoya, K. (1995). "The method of constant stimuli in testing auditory sensitivity in small birds," Methods in Comparative Psychoacoustics, edited by G. M. Klump, R. J. Dooling, R. R. Fay, and W. C. Stebbins (Birkauser, Basel), pp. 161-169.

Dooling, R. J., Ryals, B. M., Dent, M. L., and Reid, T. L. (2006). "Perception of complex sounds in Budgerigars (Melopsittacus undulatus) with temporary hearing loss," J. Acoust. Soc. Am. 119, 2524-2532.

Dooling, R. J., and Saunders, J. C. (1975). "Auditory intensity discrimination in the parakeet (Melopsittacus undulatus)," J. Acoust. Soc. Am. 58, $1308-1310$.

Dooling, R. J., and Searcy, M. H. (1979). "Relation among CRs, critical bands, and intensity difference limens in the parakeet (Melopsittacusundulatus)," Bull. Psychon. Soc. 13, 300-302.

Dooling, R. J., and Searcy, M. H. (1981). "Amplitude-modulation thresholds for the parakeet (Melopsittacus undulatus)," J. Acoust. Soc. Am. 143, 383-388.

Dooling, R. J., and Searcy, M. H. (1985). "Temporal integration of acoustic signals by the budgerigar (Melopsittacus undulatus)," J. Acoust. Soc. Am. 77, 1917-1920.

Duifhuis, H. (1973). "Consequences of peripheral frequency selectivity for nonsimultaneous masking," J. Acoust. Soc. Am. 54, 1471-1488.

Elliott, L. L. (1975). "Temporal and masking phenomena in persons with sensorineural hearing loss," Audiology 14, 336-353.

Fay, R. R. (1988). Hearing in Vertebrates: A Psychophysics Databook (HillFay Associates, Winnetka, IL).

Gardner, T. J., Naef, F., and Nottebohm, F. (2005). "Freedom and rules: The acquisition and reprogramming of a bird's learned song," Science 308, 1046-1049.

Gengel, R. W., and Watson, C. S. (1971). "Temporal integration: I. Clinical implications of a laboratory study. II. Additional data from hearingimpaired subjects," J. Speech Hear Disord. 36, 213-224.

Gescheider, G. A. (1985). Psychophysics: Method, Theory, and Application (Lawrence Erlbaum \& Associates, New York).

Glasberg, B. R., and Moore, B. C. J. (1989). "Psychoacoustic abilities in subjects with unilateral and bilateral cochlear impairments and their relationship to the ability to understand speech," J. Acoust. Soc. Am. 32, 1-25. Gleich, O., Dooling, R. J., and Manley, G. A. (1994). "Inner-ear abnormalities and their functional consequences in Belgian Waterslager canaries (Serinus canarius)," Hear. Res. 79, 123-136.

Gleich, O., Dooling, R. J., and Ryals, B. M. (2001). "A quantitative analysis of the nerve fibers in the VIIIth nerve of Belgian Waterslager canaries with a hereditary sensorineural hearing loss," Hear. Res. 151, 141-158.

Gleich, O., Klump, G. M., and Dooling, R. J. (1995). "Peripheral basis for the auditory deficit in Belgian Waterslager canaries (Serinus canarius)," Hear. Res. 82, 100-108.

Gleich, O., and Manley, G. A. (2000). "The hearing organ of birds and crocodilian," Comparative Hearing: Birds and Reptiles, edited by R. J. Dooling, R. R. Fay, and A. N. Popper (Springer, Berlin), pp. 197-248.

Güttinger, H. R. (1979). "Integration of learnt and genetically programmed behavior-Study of hierarchical organization in songs of canaries, greenfinches and their hybrids," Z. Tierpsychol 49, 285-303.

Güttinger, H. R. (1981). "Self-differentiation of song organization rules by deaf canaries," Z. Tierpsychol 56, 323-340.

Güttinger, H. R. (1985). "Consequences of domestication on the song structures in the canary," Behaviour 94, 254-278.

Hall, J. W., and Fernandes, M. A. (1983). "Temporal integration, frequency resolution, and off-frequency listening in normal-hearing and cochlearimpaired listeners," J. Acoust. Soc. Am. 74, 1172-1177.

Hienz, R. D., Sinnott, J. M., and Sachs, M. B. (1980). "Auditory intensity discrimination in blackbirds and pigeons," J. Community Psychol. 94, 993-1002.

Hughes, J. W. (1946). "The threshold of audition for short periods of stimulation," Proc. R. Soc. London, Ser. B 133, 486-490.

Klump, G. M., and Baur, A. (1990). "Intensity discrimination in the European starling (Sturnus vulgaris)," Naturwiss. 77, 545-548.

Klump, G. M., and Maier, E. H. (1989). "Gap detection in the starling (Sturnus vulgaris)," J. Comp. Physiol., A 164, 531-538.

Klump, G. M., and Maier, E. H. (1990). "Temporal summation in the European starling (Sturnus vulgaris)," J. Comp. Psychol. 104, 94-100.

Klump, G. M., Schwenzfeier, C., and Dent, M. L. (1998). "Gap detection in the barn owl (Tyto alba)," Assoc. Res. Otolaryngol. St. Petersburg, FL.

Kubke, M. F., Dent, M. L., Hodos, W., Carr, C. E., and Dooling, R. J. (2002). "Nucleus magnocellularis and nucleus laminaris in Belgian Waterslager and normal strain canaries," Hear. Res. 164, 19-28.

Kuhn, A., and Saunders, J. C. (1980). "Psychophysical tuning curves in the parakeet: A comparison between simultaneous and forward masking procedures," J. Acoust. Soc. Am. 68, 1892-1894.

Lauer, A. M., and Dooling, R. J. (2002). "Frequency selectivity in canaries with a hereditary hearing loss," J. Acoust. Soc. Am. 111, 2392.

Lauer, A. M., Dooling, R. J., and Leek, M. R. (2006). "Impaired frequency resolution in canaries with hereditary hearing loss," J. Acoust. Soc. Am. 119, 1251.

Lauer, A. M., Dooling, R. J., Leek, M. R., and Lentz, J. J. (2002). "Masking by harmonic complexes in the hearing impaired Belgian Waterslager canary," Assoc. Res. Otolaryngol. St. Petersburg, FL.

Lohr, B., Dooling, R. J., and Bartone, S. (2006). "The discrimination of temporal fine structure in call-like harmonic sounds by birds," J. Comp. Psychol. 120, 239-251.

Lohr, B. L., Lauer, A. M., Newman, M. R., and Dooling, R. J. (2004). "Hearing in the red-billed firefinch (Lagonosticta senegala) and the Spanish timbrado canary (Serinus canaria): The influence of natural and artificial selection on auditory abilities and vocal structure," Bioacoustics 14, 83-98.

Maier, E. H., and Klump, G. M. (1990). "Auditory duration discrimination in the European starling (Sturnus vulgaris)," J. Acoust. Soc. Am. 88, 616620 .

Marler, P., and Waser, M. S. (1977). "Role of auditory feedback in canary song development," J. Comp. Physiol. Psychol. 91, 8-16.

Neubauer, H., and Heil, P. (2004). "Towards a unifying basis of auditory thresholds: The effects of hearing loss on temporal integration reconsidered," J. Assoc. Res. Otolaryngol. 5, 436-458.

Nienhuys, T. G., and Clark, G. M. (1978). "Frequency discrimination following the selective destruction of cochlear inner and outer hair cells," 
Science 199, 1356-1357.

Nottebohm, F., and Nottebohm, M. (1976). "Left hypoglossal dominance in the control of canary and white-crowned sparrow song," J. Comp. Physiol., A 108, 171-192.

Nottebohm, F., and Nottebohm, M. (1978). "Relationship between song repertoire and age in the canary, Serinus canarius," Z. Tierpsychol 46, 298 305

Okanoya, K., and Dooling, R. J. (1985). "Colony differences in auditory thresholds in the canary (Serinus canarius)," J. Acoust. Soc. Am. 78, 1170-1176.

Okanoya, K., and Dooling, R. J. (1987). "Strain differences in auditory thresholds in the canary (Serinus canarius)," J. Comp. Psychol. 101, 213215.

Okanoya, K., and Dooling, R. J. (1990). "Detection of gaps in noise by budgerigars (Melopsittacus undulatus) and zebra finches (Poephila guttata)," Hear. Res. 50, 185-192.

Okanoya, K., Dooling, R. J., and Downing, J. D. (1990). "Hearing and vocalizations in hybrid Waterslager-Roller canaries (Serinus canarius)," Hear. Res. 46, 271-275.

Pedersen, C. B., and Eberling, C. (1973). "Temporal integration of acoustic energy in patients with presbyacusis," Acta Oto-Laryngol. 75, 32-37.

Prosen, C. A., Halpern, D. L., and Dallos, P. (1989). "Frequency difference limens in normal and sensorineural hearing impaired chinchillas," J. Acoust. Soc. Am. 85, 1302-1313.

Ryals, B. M., and Dooling, R. J. (2002). "Development of hair cell stereovilli bundle abnormalities in Belgian Waterslager canary," Assoc. Res. Otolaryngol. St. Petersburg, FL.

Saunders, S. S., and Salvi, R. J. (1993). "Psychoacoustics of normal adult chickens: thresholds and temporal integration," J. Acoust. Soc. Am. 94, 83-90.

Saunders, S. S., Salvi, R. J., and Miller, K. M. (1995). "Recovery of thresh- olds and temporal integration in adult chickens after high-level $525-\mathrm{Hz}$ pure-tone exposure," J. Acoust. Soc. Am. 97, 1150-1164.

Schroeder, M. R. (1970). "Synthesis of low-peak-factor signals and binary sequences with low autocorrelation," IEEE Trans. Inf. Theory 16, 85-89.

Sek, A., and Moore, B. C. J. (1995). "Frequency discrimination as a function of frequency, measured in several ways," J. Acoust. Soc. Am. 97, 2479-2486.

Sinnott, J. M., Sachs, M. B., and Hienz, R. D. (1980). "Aspects of frequency discrimination in passerine birds and pigeons," J. Comp. Physiol. Psychol. 94, 401-415.

Solecki, J., and Gerken, G. M. (1990). "Auditory temporal integration in the normal-hearing and hearing-impaired cat," J. Acoust. Soc. Am. 88, 779785 .

Turner, C. W., Zwislocki, J. J., and Filion, P. R. (1989). "Intensity discrimination determined with two paradigms in normal and hearing-impaired subjects," J. Acoust. Soc. Am. 86, 109-115.

Viemeister, N. F. (1988). "Psychophysical aspects of auditory intensity coding," Auditory Function, edited by G. M. Edelman, W. E. Gall, and W. A. Cowan (Wiley, New York), pp. 213-241.

Waser, M. S., and Marler, P. (1977). "Song learning in canaries," J. Comp. Physiol. Psychol. 91, 1-7.

Weisleder, P., Lu, Y., and Park., T. J. (1996). "Anatomical basis of a congenital hearing impairment: basilar papilla dysplasia in the Belgian Waterslager canary," J. Comp. Neurol. 369, 292-301.

Weisleder, P., and Park., T. J. (1994). "Belgian Waterslager canaries are afflicted by Scheibe's-like dysplasia," Hear. Res. 80, 64-70.

Wright, T. F., Brittan-Powell, E. F., Dooling, R. J., and Mundinger, P. (2004). "Sex-linkage of deafness and song frequency spectrum in the Waterslager strain of domestic canary," Biol. Letters 271, s409-s412.

Wright, T. F., Cortopassi, K. A., Bradbury, J. W., and Dooling, R. J. (2003). "Hearing \& vocalizations in conures," J. Comp. Psychol. 117, 87-95. 